\title{
PAULO FREIRE EM AOTEAROA - NOVA ZELÂNDIA: UMA DISCUSSÃO SOBRE A PRODUÇÃO DE PETER ROBERTS $^{*}$
}

\author{
PAULO FREIRE IN AOTEAROA - NEW ZEALAND: A DISCUSSION \\ ON THE PRODUCTION OF PETER ROBERTS
}

PAULO FREIRE EN AOTEAROA - NUEVA ZELANDIA: UNA DISCUSIÓN
SOBRE LA PRODUCCIÓN DE PETER ROBERTS

Gabriela Medeiros Nogueira**

(iD) http://orcid.org/oooo-0oo2-6985-064X

Eduardo Arriada ${ }^{* * *}$

https://orcid.org/oooo-ooo1-5216-2739

Mônica Maciel Vahl****

https://orcid.org/oooo-ooo2-68oo-1742

REVISTA PEDAGÓGICA

Revista do Programa de Pós-graduação em Educação da Unochapecó | ISSN 1984-1566 Universidade Comunitária da Região de Chapecó | Chapecó-SC, Brasil Como referenciar este artigo: NOGUEIRA, G. M.; ARRIADA, E.; VAHL, M. M. Paulo Freire em Aotearoa - Nova Zelândia: uma discussão sobre a produção de Peter Roberts. Revista Pedagógica, Chapecó, v. 21, p. 431-446, 2019. DOI: http://dx.doi.org/10.22196/rp.v22io.489o

RESUMO: Buscamos com este trabalho dar visibilidade à discussão da obra de Freire em Aotearoa - Nova Zelândia, a partir da produção acadêmica de Peter Roberts, professor na University of Canterbury. Realizamos uma busca bibliográfica em artigos, capítulos de livros e livros organizados pelo autor neozelandês desde os anos 1980. Entrevistamos o professor ampliando dados sobre como Freire passa a ser conhecido e estudado na Nova Zelândia. Assim, pudemos conhecer sobre o contexto da produção acadêmica e da prática didática que Roberts vem realizando nas últimas três décadas. Ao longo do texto, destacamos as seguintes estratégias de produção de Peter Roberts: i) estudos comparativos entre Freire e autores de obras literárias e/ou filosóficas; ii) acompanhamento da produção de Freire ao longo do tempo sem perder a dimensão histórica; iii) análise de autores que criticam Freire e, a partir de seus postulados, tecem argumentos justificativos que demonstram certa fragilidade nas críticas elaboradas.

Palavras-chave: Paulo Freire. Nova Zelândia. Peter Roberts. Produção acadêmica.

ABSTRACT: With this paper we aim at discussing Freire's work in Aotearoa - New Zealand, making it visible through the academic production of Professor Peter Roberts at the University of Canterbury. In doing so, firstly, we have carried out a bibliographical search of articles, book chapters and books organized by the New Zealand author since the 1980 . Secondly, we interviewed the professor himself so as to gather data on how Freire came to be known and studied in New Zealand. In this way, we were able to learn about the context of academic production and the didactic practice that Roberts has been realising in the last three decades. Throughout the paper, we highlight the following production strategies of Peter Roberts: i) comparative studies between Freire and authors of literary and/or philosophical works; ii) monitoring the production of Freire over time without losing the historical dimension; iii) analysis of authors who criticize Freire, and, on the basis of their claims, construction of arguments that demonstrate a certain fragility of the criticisms made.

Keywords: Paulo Freire. New Zealand. Peter Roberts. Academic production.

RESUMEN: Buscamos con este trabajo dar visibilidad al estudio de la obra de Paulo Freire en Aotearoa - Nueva Zelandia, a partir de la producción académica de Peter Roberts, profesor en la Universidad de Canterbury. Realizamos una búsqueda bibliográfica de artículos, capítulos de libros y libros organizados por el autor neozelandés desde los años 1980. Entrevistamos al profesor con el objetivo de ampliar la información con que contábamos sobre como Freire fue conocido y es estudiado en Nueva Zelandia. De esta manera pudimos conocer el contexto de la producción académica y la práctica didáctica que Roberts ha desarrollado en las últimas tres décadas. A lo largo de este texto, establecimos las siguientes categorías en la producción de Peter Roberts: I) análisis comparativos entre Freire y otros autores de obras literarias y ó filosóficas; II) estudio de la producción de Freire a lo largo del tiempo sin perder la dimensión histórica; III) examen de los autores que criticaron a Freire, a partir de sus postulados, tesis argumentales y justificativos, que demuestran cierta fragilidad en las críticas elaboradas.

Palabras clave: Paulo Freire. Nueva Zelandia. Peter Roberts. Producción académica. 


\section{Introdução}

O recrudescimento do conservadorismo e o crescimento de novas ondas neoliberais estão sendo observados em discursos de representantes políticos e religiosos. $\mathrm{Na}$ conjuntura atual brasileira, Paulo Freire e sua obra são cotidianamente vilipendiados em blogs de opinião na internet, em vídeos no You Tube e até mesmo por integrantes do atual governo brasileiro ${ }^{1}$. Freire, patrono da educação brasileira desde 2012, tornou-se alvo preferido de grupos como Movimento Dogma, Escola Sem Partido e Lei da Mordaça. ${ }^{2}$ Dessa forma, é preciso questionar: Por que Freire, autor reconhecido mundialmente como um dos grandes pensadores da humanidade, com vasta obra traduzida para diferentes idiomas, vem sofrendo constantes ataques, em sua grande maioria, superficiais e vulgares?

Talvez o repudiado em Freire seja sua insistência em afirmar que a educação é um ato político e não pode nunca ser concebida como um campo neutro. Ou, quem sabe, por que ele assegura que umas das formas mais atrozes de ideologia é dizer que não há ideologia. Incomoda, quiçá, quando Freire defende que o professor merece ser reconhecido por seu trabalho e receber um salário compatível à responsabilidade que tem de ensinar crianças e jovens. Quem sabe, ainda, o ponto crucial de desconforto seja a convicção de que os oprimidos podem mudar o mundo por meio de sua conscientização.

Nesse contexto, é importante rememorar que Paulo Freire é estudado e discutido nas grandes universidades internacionais e é reconhecido mundialmente como um dos maiores educadores nos últimos tempos. Ele obteve mais de 40 títulos de doutor honoris causa, concedido por diversas universidades no Brasil e no exterior. Além disso, de acordo com levantamento feito pelo pesquisador Elliott Green no banco de dados do Google Scholar, "Pedagogia do Oprimido" é a terceira obra mais utilizada em trabalhos no campo das ciências humanas, com cerca de 72.359 citações (GREEN, 2016).

Considerando isso, com este trabalho, buscamos dar visibilidade à discussão da obra de Freire em Aotearoa Nova Zelândia. Para tanto, observamos a produção acadêmica de Peter Roberts, professor na University of Canterbury. Realizamos uma busca bibliográfica em artigos, capítulos de livros e livros organizados pelo autor neozelandês desde final da década de 1980. Além disso, tivemos a oportunidade de entrevistá-lo, o que possibilitou ampliar dados de como Freire passa a ser conhecido e estudado na Nova Zelândia. Pudemos, também, conhecer sobre o contexto da produção acadêmica e da prática didática que Roberts vem realizando nas últimas três décadas.

Na primeira seção do artigo, apresentamos dados de um projeto de colaboração internacional, intitulado "Mostra Internacional Itinerante alusiva aos 20 anos de morte de Paulo Freire", que deu origem, em 2017, à interlocução

\begin{abstract}
* Aotearoa (Terra da Nuvem Branca) é como os Maoris denominam o país, conhecido mundialmente por Nova Zelândia.

Aotearoa (White Cloud Land) is how the Maoris call the country, known worldwide as New Zealand.

Aotearoa (Terra da Nuvem Branca) es como los Maoris denominam o país, conocido mundialmente por Nova Zelândia.

** Professora no Instituto de Educação da Universidade Federal do Rio Grande-FURG. Atua no Programa de Pós-graduação da FURG. Coordena o Grupo de Estudo e Pesquisa em Alfabetização e letramento - GEALI, cadastrado no diretório acadêmico do CNPq.

E-mail: gabynogueira@me.com
\end{abstract}

*** Professor associado da Faculdade de Educação da Universidade Federal de Pelotas. Atua no Programa de Pós-graduação. Vinculado ao Centro de Estudos e Investigação em História da Educação. Coordena o Centro de Documentação CEDOC.

E-mail: earriada@me.com

**** Doutora em Educação pela University of Canterbury (UC). Integrante dos grupos de pesquisa HISALES (História da Alfabetização, Leitura, Escrita e dos Livros Escolares - FaE/UFPEL), do Grupo de Estudo e Pesquisa em Alfabetização e Letramento (GEALI - IE/FURG) e School of Educational Studies and Leadership (UC).

E-mail: monicamvahl@gmail.com

1 Consultar: "Paulo Freire - o Patrono da Educação Brasileira (Olavo de Carvalho)" neste link: https://www. youtube.com/watch?v=-Mlc68kAuA8; "Eduardo Bolsonaro escracha Paulo Freire e desmascara Jandira Feghali" em: https://www.youtube.com/ watch?v=a7oOzAL8Vyc; e "Por que Paulo Freire incomoda tanto Bolsonaro?" em: https://www.youtube. com/watch?v=a2sbL6vSf_o

2 Em abril de 2019, Sérgio Haddad publicou um artigo na Folha de São Paulo, ressaltando que o próprio Freire, ao conceder uma entrevista publicada no Caderno "Mais" do mesmo jornal, em 29 de maio de 1994, declarou as razões pelas quais seu método não erradicou o analfabetismo no Brasil. Freire disse que: "Em tese o analfabetismo poderia ter sido erradicado com ou sem Paulo Freire. O que faltou foi decisão política. A sociedade brasileira é profundamente autoritária e elitista" (HADDAD, 2019). 
entre pesquisadores no Brasil e na Nova Zelândia. Na segunda seção, discorremos sobre Peter Roberts e seus encontros com as ideias de Freire. Na terceira seção, trazemos dados sobre a produção de Peter Roberts ao longo de mais de 30 anos. Por fim, na quarta seção demostramos algumas facetas de como Freire é lido, interpretado e analisado por esse autor.

\section{Mostra internacional itinerante alusiva aos 20 anos de morte de Paulo Freire: refletindo sobre a pedagogia do oprimido}

Referente aos 20 anos de morte de Paulo Freire, foi realizado um projeto de colaboração interinstitucional envolvendo os seguintes países Brasil, Uruguai, Argentina, Estados Unidos e Nova Zelândia a fim de criar um ambiente de diálogo sobre o legado de Paulo Freire, em especial da Pedagogia do Oprimido. Dentre os objetivos deste projeto, destacamos: i) analisar as diferentes edições e prefácios da obra Pedagogia do Oprimido; ii) discutir a relevância da obra Pedagogia do Oprimido após 47 anos de sua primeira edição, publicada inicialmente em inglês e posteriormente em espanhol, português, francês, alemão, italiano e japonês; iii) divulgar pesquisas recentes sobre Paulo Freire e a Pedagogia do Oprimido e iv) contribuir para que a importância do legado de Paulo Freire continue sendo conhecida e valorizada no Brasil e em diferentes países.

Entendemos que o principal ganho deste projeto foi a possibilidade de reafirmar a influência e a vigência do pensamento de Paulo Freire nas experiências educativas, tanto dos países envolvidos na mostra como outros tantos espalhados pelos cinco continentes. Dentre os diversos livros que fizeram parte da mostra em língua portuguesa, elencamos, no quadro a seguir, as obras publicadas em diversos idiomas:

Quadro 1 - Edições da Pedagogia do Oprimido que compuseram a Mostra Internacional Itinerante

\begin{tabular}{|l|c|c|c|c|}
\hline Obra & Língua/ país & Tradutor & Editor & Ano \\
\hline Pedagogy of the Oppressed & Estados Unidos & Myra Bergman Ramos & Herder and Herder & 1970 \\
\hline Pedagogia del Oprimido & Uruguai & Jorge Mellado & Tierra Nueva & 1970 \\
\hline La Pedagogia degli Oppressi. & Itália & Linda Bimbi & Arnoldo Mandadori Editore & 1971 \\
\hline Pådagogik der Unterdrückten & Alemanha & Ernst Lange & Kreuz-Verlag & 1971 \\
\hline Pedagogia del Oprimido & Argentina & Jorge Mellado & Siglo XXI-Tierra Nueva & 1973 \\
\hline Pedagogia do Oprimido & Brasil & & Paz e Terra & 1974 \\
\hline $\begin{array}{l}\text { Pedagogie des Oprimes suivi de } \\
\text { conscientisation et revolution. }\end{array}$ & França & Librairie François Maspero & 1974 \\
\hline $\begin{array}{l}\text { Hiyokuatsusha no Kyoikunaku. } \\
\text { Pedagogy of the Oppressed }\end{array}$ & Inglaterra & $\begin{array}{c}\text { Yusaku Ozawa e Tetsuji } \\
\text { Yamamoto }\end{array}$ & AkiShobo & 1979 \\
\hline
\end{tabular}

Fonte: Acervo pessoal dos autores (2019). 
A partir das diferentes edições da Pedagogia do Oprimido $^{3}$ e de estudos sobre Freire, foram elaborados banners, fichas descritivas e linha do tempo para a exposição. Esse material, impresso nas três línguas (português, inglês e espanhol), foi apresentado em Christchurch (Nova Zelândia), em Pelotas, Rio Grande e Passo Fundo (Brasil), em Salto (Uruguai), com perspectiva de ser apresentado na Argentina e nos Estados Unidos em 2021. Cabe ainda destacar que em cada uma dessas localidades a exposição ocorreu em conjunto com um seminário ou uma conferência sobre o campo da educação, alcançando, assim, um público significativo.

Desse modo, em 10 de julho de 2017, juntamente com a mostra itinerante, foi realizado o seminário "Repensando o legado de Paulo Freire: educação, política e ética" 4 na University of Canterbury. Este foi um momento de discussão bastante profícuo que reverberou na ampliação e continuidade do trabalho em rede internacional, em especial, com o professor Peter Roberts.

A seguir, discorremos sobre a trajetória profissional de Peter Roberts relativa ao pensamento de Paulo Freire.

\section{Diálogos entre Peter Roberts e Paulo Freire: pensando a teoria, pensando a prática}

Peter Roberts é professor na University of Canterbury, em Christchurch, na Nova Zelândia. Atualmente ele está vinculado a Escola de Educação, Estudos e Liderança ${ }^{5}$ e desenvolve pesquisas nas linhas de Filosofia da Educação ${ }^{6}$ e Estudos de Política Educacional. ${ }^{7}$ Anteriormente ele também trabalhou na University of Auckland e na University of Waikato ${ }^{8}$. As principais temáticas investigadas são: filosofia da educação, ética, política e educação, literatura e educação. Além disso, ressalta-se que Roberts vem pensando e publicando extensivamente sobre Paulo Freire nas últimas três décadas.

Conforme Roberts relatou em entrevista realizada em 18 de abril de 2019, ele foi apresentado ao trabalho de Freire por Colin Lankshear, na Universidade de Auckland, no início dos anos 1980. Conforme suas palavras: "Colin foi um mentor importante para mim e ele era um professor inspirador. Freire apareceu perto do final de um curso que ele ensinou (com Jim Marshall) sobre o pensamento educacional ocidental" (ROBERTS, 2019). Ao conhecer o trabalho de Freire, Roberts percebeu o quanto suas ideias eram potentes e considerou a possibilidade de estudar esse autor com maior profundidade. Assim, foi em sua dissertação de mestrado em Auckland, na qual tratou sobre o conceito de conscientização em Freire (ROBERTS, 2009).

Um fato interessante destacado por Roberts é que o início de sua vida acadêmica, em 1988, coincidiu com um período extraordinariamente produtivo em termos de publicação na vida de Freire. "Na década anterior à sua morte, em 1997, Freire publicou inúmeros livros, tanto
3 Pedagogia do Oprimido, obra originalmente publicada em inglês no ano de 1970, e logo traduzida para diversas línguas, inclusive para língua portuguesa em 1974 .

4 O seminário Rethinking Paulo Freire's legacy: education, politics and ethics contou com apresentações de trabalho de pesquisadores da University of Canterbury (UC), University of Illinois at Urbana-Champaign (UIUC), Universityof Hong Kong, Universidade Federal de Pelotas (UFPel) e Universidade Federal do Rio Grande (FURG).

5 School of Educational Studies and Leadership.

6 Philosophy of Education.

7 Educational Politics Studies.

8 Roberts também atuou como presidente da Philosophy of Education Society of Australasia (PESA).

9 Colin was an important mentor for me and he was an inspiring teacher. Freire appeared near the end of a course he taught (with Jim Marshall) on Western educational thought (ROBERTS, 2019). 
sozinho quanto em colaboração com outros, de modo que não havia escassez de material novo para acompanhar" (ROBERTS, 2019).

É preciso salientar que as principais obras de Paulo Freire tiveram publicação em língua inglesa. Inclusive, muito de seus trabalhos, alguns destes em parceria com autores norte-americanos, foram publicados antes em inglês e posteriormente traduzidos para a língua portuguesa. $\mathrm{O}$ acesso aos escritos de Freire em língua inglesa amplia barbaramente o expecto de leitores e pesquisadores de sua obra, motivo pelo qual, Freire tem uma repercussão mundial, além, obviamente, da relevância de suas ideias. Observando a bibliografia arrolada nas produções de Peter Roberts, percebemos que ele se pautou exclusivamente nas obras publicadas em língua inglesa.

Por outro lado, no Brasil, muitas vezes, não chegamos a ter acesso à publicação de pesquisadores estrangeiros que têm Freire como referência, justamente pela dificuldade com a língua inglesa. Ainda é diminuto o número de pesquisadores brasileiros que leem e escrevem em inglês, motivo pelo qual suspeitamos que o trabalho de Roberts não seja amplamente conhecido no Brasil. Além disso, temos maior acesso no Brasil à produção de pesquisadores norte-americanos, com textos traduzidos para a língua portuguesa, como é o caso de Henry Giroux, Peter McLaren, Peter Leonard, Michael Apple, Roger Simon e Colin Lankshear.

Talvez isso se deva ao fato de Paulo Freire ter morado nos Estados Unidos entre abril de 1969 e fevereiro de 1970 e ter tido uma grande inserção na intelectualidade estadunidense. Este fato, amplia as conexões de pesquisa entre brasileiros e norte-americanos.

Com relação à produção de Freire, Roberts salienta, em seu artigo "Após dez anos: engajando o trabalho de Paulo Freire no século 21"11 (2007), que, a partir de 1987, Freire desfrutaria de um "segundo fôlego" como escritor. Ao que tudo indica, esse período de produção, muitas delas coletivamente, configurou-se em uma série de textos dialógicos, escritos na forma de conversas estruturadas entre ele e seus coautores, tais como: Ira Shor ${ }^{12}$, Donaldo Macedo ${ }^{13}$, Antônio Faundez ${ }^{14}$, Myles Horton ${ }^{15}$. Esses trabalhos discutem questões práticas e teóricas.

Além dos artigos publicados coletivamente, observamos também que escreveu textos ancorados na sua participação política, caso da "Educação da Cidade" (1991), cujas reflexões são decorrências de sua atuação como Secretário da Educação do Município de São Paulo, durante a administração de Luíza Erundina.

Na década de 1990, Freire escreve ainda "Pedagogia da Esperança: um reencontro com a Pedagogia do Oprimido"(1992), livro que recupera os temas suscitados pela Pedagogia do Oprimido e que permaneceram como núcleo de debates sociais e educacionais. A obra sintetiza as grandes temáticas gestadas nas lutas sociais que convulsionaram
10 In the decade before his death in 1997, Freire published numerous books, both alone and in collaboration with others, so there was no shortage of new material to engage (ROBERTS, 2019).

11 Tenyearson: Engaging the work of Paulo Freire in the 21st century.

12 FREIRE, Paulo; SHOR, Ira. A pedagogy for liberation. London: MacMillan, 1987. [Medo e Ousadia. Rio de Janeiro: Paz e Terra, 1986].

13 FREIRE, Paulo; MACEDO, Donaldo - Literacy: Reading the word and the world. London: Routledge, 1987. [Alfabetização: leitura do mundo, leitura da palavra. Rio de Janeiro: Paz e Terra,1990].

14 FREIRE, Paulo; FAUNDEZ, Antonio. Learning to question: A pedagogy of liberation. Geneva: World Council of Churches, 1989. [Por uma Pedagogia da pergunta. Rio de Janeiro: Paz e Terra, 1985].

15 HORTON, Myles; Freire, Paulo. We make the road by walking: Conversation son education and social change. Philadelphia: Temple University Press, 1990. [O caminho se faz caminhando. Rio de Janeiro: Paz e Terra, 2003]. 
a América Latina e os povos do Terceiro Mundo, fazendo brotar uma pedagogia da esperança. Além disso, Freire também publica "Pedagogia da Autonomia" (1994), em que discute temas como ética, política, identidade, bom senso, ideologia e conhecimento. Nessa obra, ele evidencia como o discurso do neoliberalismo está permeado de manipulações e incoerências, que trabalham para ocultar profundas desigualdades sociais e econômicas.

Ao refletir sobre a atualidade e validade do pensamento de Paulo Freire, Roberts expressa um olhar crítico, humilde e generoso sobre o autor e sobre si mesmo:

Algumas das principais virtudes éticas $e$ educacionais adotadas por Freire - cuidado, compromisso, humildade, atenção, abertura e rigor, por exemplo - fornecem ideais aos quais aspiro. Há sempre mais trabalho a fazer para trazer essas virtudes à vida, mas essa também é uma das lições que Freire nos ensinou: permanecemos seres inacabados, $e$ nossa própria educação deve ser um processo vitalício. (ROBERTS, 2019) ${ }^{16}$.

Além dos aspectos citados por Roberts no excerto anterior, cabe ressaltar também que para Freire a educação é um processo humanizador entre quem ensina e quem aprende, por meio do diálogo que descontrói hierarquias. Ao abordar o modelo vigente em sua época, Freire cria a expressão "educação bancária" como uma metáfora à educação, ou seja, o conhecimento é compreendido como algo que pode ser depositado e/ou transferido para os estudantes, assim como em um banco onde o dinheiro é depositado. Na obra "Pedagogia do Oprimido", essa correlação é bastante evidenciada nas seguintes colocações: "[...] a) o educador é o que educa; os educandos, os que são educados; b) o educador é o que sabe; os educandos, os que não sabem; c) o educador é o que pensa; os educandos, os pensados [...]" (FREIRE, 1974, p. 34).

A educação como processo humanizador é destacada por Roberts durante a entrevista, especialmente no âmbito docente, uma vez que considera que Freire apresenta-se como um autor potente na reflexão sobre o fazer pedagógico e na relação entre teoria e prática, conforme relatado na entrevista:

Freire, por meio do seu próprio exemplo, permite aos professores ver como a teoria e a prática podem e devem ser interligadas. Ele ajuda os professores a apreciar a importância dos principais princípios pedagógicos subjacentes, sem ficarem obcecados com métodos e técnicas. Ele nos lembra de pensar profundamente sobre os propósitos de ensinar e aprender, e o valor da vida humana. (ROBERTS, 2019). ${ }^{17}$
16 Some of the key ethical and educational virtues Freire espoused - care, commitment, humility, attentiveness, openness, and rigour, for example - provide ideals to which I aspire. There is always more work to do in trying to bring those virtues to life, but that too is one of the lessons Freire taught us: we remain unfinished beings, and our own education must be a lifelong process (ROBERTS, 2019).

17 Freire, through his own example, allows teachers to see how theory and practice can and should be intertwined. $\mathrm{He}$ helps teachers to appreciate the importance of key underlying pedagogical principles, without becoming obsessed with methods and techniques. He reminds us to think deeply about the purposes of teaching and learning, and the value of human life (ROBERTS, 2019). 
Há um longo e exaustivo percurso em que Freire coloca sua preocupação com o diálogo, com o comprometimento e com a tolerância, como bases fundamentais de uma epistemologia voltada para a formação de professores. Nesse mesmo sentido, Roberts comenta que, com Freire, aprendeu "[...] a importância de um diálogo estruturado e intencional e tento promovê-lo nas salas de aula das universidades", procurando encorajar "[...] os alunos a fazer perguntas e fazer conexões entre as ideias que consideramos e as questões pessoais, sociais e políticas mais amplas" (ROBERTS, 2019) ${ }^{18}$.

Observamos assim, nas palavras de Roberts, uma prática dos postulados de Freire ao afirmar que a educação define-se pela liberdade, cuja busca é determinada pela consciência-mundo do sujeito. Para obtermos a liberdade, é preciso refletir sobre a realidade concreta; assim o fazendo, descobrimos que não estamos apenas no mundo, mas com o mundo e com os outros. No entanto, essa busca é feita na materialidade da vida cotidiana. Desse modo, a partir de Freire, Roberts considera que: "[...] há limites para o que a educação pode fazer, mas também não há dúvida de que o ensino pode desempenhar um papel crucial na transformação das vidas humanas" (ROBERTS, 2019) ${ }^{19}$.

Nesse sentido, é fundamental considerar que o ato de ensinar implica uma atitude de compromisso e profundo respeito pelo saber do outro. Para Freire, o vital e o necessário no ato de ensinar é que: "ensinar exige segurança, competência profissional e generosidade" (FREIRE, 1994, p. 102). Freire, também destaca o diálogo como ferramenta política-epistemológica para a superação da alienação, possibilitando, desse modo, uma conscientização maior em que a educação implica mudança. O que agrega educador e educando é o conhecimento construído historicamente. A importância do diálogo está na reflexão daqueles envolvidos numa relação dialógica, tornando-nos mais próximos, e do mesmo modo, juntam-se forças para compreender e quem sabe transformar/mudar o mundo.

Na seção seguinte, apresentamos dados da produção de Peter Roberts sobre Freire ao longo de 30 anos, salientando recorrências e continuidades.

\section{Um levantamento dos escritos de Peter Roberts sobre Paulo Freire}

O primeiro texto de Peter Roberts sobre Paulo Freire tem como data de publicação o ano de 1989. Observando seu currículo vitae, percebemos que não se trata de uma publicação pontual e esporádica sobre Freire, pois reflexões sobre diferentes aspectos da obra freireana são recorrentes em sua trajetória, conforme é possível perceber no quadro a seguir:
18 From Freire, I have learned the importance of structured, purposeful dialogue, and I try to promote this in university classrooms. I encourage students to ask questions and to make links between the ideas we consider and wider personal, social and political concerns (ROBERTS, 2019).

19 As Freire frequently noted, there are limits to what education can do, but there is also no doubt that teaching can play a pivotal role in transforming human lives (ROBERTS, 2019). 
Quadro 2 - Produção acadêmica de Peter Roberts sobre Paulo Freire

\begin{tabular}{|c|c|c|c|}
\hline Tipo de publicação & Total & $\begin{array}{c}\text { Menciona } \\
\text { Freire no título }\end{array}$ & Ano \\
\hline Artigos & 89 & 21 & $\begin{array}{c}2017(2) ; 2016 ; 2015 \\
2012 ; 2009 ; 2007(2) \\
2005(3) ; 2004 ; 2003(2) ; 1998(2) ; 1997 ; \\
1996(2) ; 1994 ; 1989\end{array}$ \\
\hline Capítulo de livros & 23 & 7 & 2017 (2); 2016; 2008 (2); 2003; 1999 \\
\hline Livros & 10 & 3 & 2016; 2010; 2002 \\
\hline Organização de Livros & 5 & 1 & 1999 \\
\hline
\end{tabular}

Fonte: Elaborado pelos autores a partir do currículo vitae fornecido por Roberts.

De acordo com os dados organizados no Quadro 2, a produção acadêmica de Peter Roberts concentra-se em artigos científicos publicados em periódicos, livros, capítulos de livros e livros organizados por ele. Dentre os artigos, foram 89 publicados desde 1989 até 2017; e destes, 21 tratam diretamente sobre Freire. Na sequência, localizamos produção em capítulos de livros, e 23 deles foram publicados entre 1999 e 2007, dos quais, sete são diretamente relacionados a Freire. Entre 2002 e 2016, Roberts publicou dez livros, dos quais três focam majoritariamente em Freire. Além disso, Roberts organizou cinco livros, em que um deles também é especificamente sobre Freire. Portanto, na totalidade de suas produções, 33 têm como temática aspectos da obra de Paulo Freire.

Tomando como referência a produção de Roberts, de forma longitudinal, percebemos que os anos de maior publicação, em termos quantitativos, sobre Freire foram 2017 e 2016, sendo quatro e três produções publicadas respectivamente. Identificamos em 2005 e 2003 dois picos de produção; e, em cada um dos referidos anos, ocorreram três publicações. Em 2007, 1999, 1998 e 1996, Roberts teve duas publicações em cada ano. Nos anos de 2015, 2012, 2010, 2009, 2008, 2004, 2002, 1997, 1994 e 1989 Roberts teve uma produção publicada em cada ano, mas em $2014 \mathrm{e}$ 2013 não houve publicação diretamente vinculada a Freire, nem em 2011, 2006, 2001 e 2000 ${ }^{20}$.

Considerando esse panorama inicial é possível afirmarmos que, de forma profícua, o professor Peter Roberts vem, desde os anos 1980, estudando, pesquisando e produzindo diversos trabalhos tendo como centralidade de análises as ideias de Paulo Freire - por exemplo, Roberts (1996a, 1996b, 1996c, 1997, 1998, 1999a, 1999b, 2002, 2003a, 2003b, 2005a, 2005b, 2007, 2007a, 2008, 2010, 2013, 2015). Embora tenha publicado extensivamente sobre Freire, ele nunca se viu como um "seguidor". Ao contrário, gosta de imaginar Freire como um "companheiro de viagem", alguém com quem caminhar junto, dialogar, discutir e discordar ${ }^{21}$.

Conforme relata em entrevista:

Embora Freire tenha sido uma figura-chave em minha vida intelectual e pedagógica, ele
20 Nossa intenção com essa contagem foi apenas a quantificação da produção por ano. Temos clareza que não é possível medir a qualidade e o envolvimento despendido em uma produção, pois, em geral, o tempo na escrita de um livro é muito diferente do que na escrita de um artigo.

21 “As I have noted elsewhere (ROBERTS, 2010). I have never seen myself as a 'follower' of Freire. Rather, I think of myself as a 'fellow traveller'. As teachers, researchers and citizens, we are all trying to find our way in the world, and Freire can help us on that journey, but that does not mean we need to agree with everything he has written, support everything he has done, or seek a blueprint for our own activities in his work" (ROBERTS, 2019). 
obviamente não foi a única influência no meu trabalho. Minha leitura de outros pensadores e romancistas, como Kierkegaard, Nietzsche, Dostoiévski, Unamuno, Weil, Hesse, Camus, Beauvoir e Murdoch, ajudou-me a entender melhor as potencialidades $e$ limitações do trabalho de Freire. (ROBERTS, 2019) $)^{22}$.

A partir das colocações de Roberts no decorrer da entrevista, percebemos a amorosidade e humildade, ao utilizar conceitos freireanos, que o pesquisador expressa ao citar os diferentes autores que lhe ajudaram a compreender a teoria e os pressupostos de Freire. Consideramos que ler, compreender e escrever sobre qualquer aspecto da obra de Paulo Freire, sempre é um imenso desafio, por ser uma produção multifacetada, envolvendo outros campos de saber além da pedagogia.

Roberts, no decorrer da entrevista, explica qual a perspectiva tem utilizado em relação a Freire:

Tenho discutido sobre uma abordagem holística, contextualizada e antitecnocrática na busca de entender o trabalho de Freire (Roberts, 200o). À medida que minha leitura de outros autores se expandiu, refleti sobre a teoria freireana no tratamento de questões relativas à diferença (Roberts, 2003a), razão e emoção (Roberts, 2008), pós-modernidade (Roberts, 2003b), neoliberalismo (Roberts, 2010), ensino superior (Roberts, 2017a), felicidade, esperança e desespero (Roberts, 2016) e utopia (Roberts \& Freeman-Moir, 2013). (ROBERTS, 2019) ${ }^{23}$.

A trajetória intelectual de Peter Roberts evidencia o quanto se dedicou com afinco a entender o pensamento de Freire bem como conceitos discutidos por ele. A opção por fazer essa caminhada junto a outros autores - por exemplo, Kierkegaard e Nietzsche - demonstram uma estratégia interessante à medida que não restringe o pensamento do autor em si mesmo. Ao contrário, essa atitude possibilita um diálogo profícuo com a teoria de Freire, instrumentalizando, de forma mais consistente, um entendimento de categorias-chave como: razão, utopia, diferença, pós-modernidade. Com isso, uma nova dimensão de análise e compreensão de Freire fica evidenciada.

\section{Discutindo a obra de Peter Roberts}

Ao discutir a obra de Peter Roberts, adotamos uma postura aberta, mas criteriosa, disposta ao diálogo e a trocas. Roberts (1996a, 1996b, 1996c, 1997, 1998, 2003, 2007, 2015), em suas publicações, aprofunda a discussão de aspectos centrais em Freire, tais como: alfabetização crítica,
22 While Freire has been a key figure in my intellectual and pedagogical life, he has, of course, not been the only influence on my work. My reading of other thinkers and novelists such as Kierkegaard, Nietzsche, Dostoevsky, Unamuno, Weil, Hesse, Camus, Beauvoir, and Murdoch has helped me to better understand the strengths and limitations of Freire's work.

23 I have argued for a holistic, contextualised, anti-technocratic approach in seeking to understand Freire's work (ROBERTS, 2000). As my reading of other bodies of scholarship expanded, I have reflected on Freirean theory in addressing questions relating to difference (ROBERTS, 2003a), reason and emotion (ROBERTS, 2008), postmodernity (ROBERTS, 2003b), neoliberalism (ROBERTS, 2010), higher education (ROBERTS, 2017a), happiness, hope and despair (ROBERTS, 2016), and utopia (ROBERTS; FREEMAN-MOIR, 2013). 
educação e política, conscientização, humanização e utopia. Suas escritas demonstram o modo como ele foi refletindo e analisando o posicionamento de Freire, indicando suas fragilidades e retomando críticas que outros autores teceram em relação a alguns aspectos da obra de Freire. Segundo o próprio Roberts coloca durante a entrevista:

Freire encorajou ativamente seus leitores a adotarem uma postura crítica ao encontrar seu trabalho. Para mim, como para Freire, tal postura também deve ser respeitosa. Precisamos dar a um autor uma audiência justa, procurando o que é potencialmente valioso em seu trabalho, enquanto também estamos dispostos a fazer alguns questionamentos. Deveríamos, como diria Freire, estar pronto para desafiar e ser desafiado pelo que estamos lendo. (ROBERTS, 2019) ${ }^{24}$.

No artigo "Estrutura, direção e rigor na educação libertadora" 25 (ROBERTS, 1996c), Roberts assinala que a discussão de Freire sobre "educação bancária" e "educação problematizadora" na "Pedagogia do Oprimido" exerceu considerável influência entre os educadores tanto do Terceiro Mundo quanto do Primeiro Mundo. Ressalta ainda a importância dessa obra, mas argumenta que ela deve ser lida concomitantemente às publicações subsequentes que expandem outros aspectos da visão freiriana de uma educação libertadora, por exemplo: neoliberalismo, globalização, autonomia, politicamente correto, entre outros. Centrando nos livros posteriores, sobre estrutura, direção e rigor na educação libertadora, ele argumenta que a pedagogia de Freire, pode ser mais bem entendida não como um "método", mas como uma abordagem distinta de teoria e prática da educação.

Por sua vez, quanto ao artigo "Conhecimento, diálogo e humanização: a filosofia moral de Paulo Freire ${ }^{26}$ (1998), Roberts considera as dimensões metafísica, ontológica, epistemológica e ética do pensamento de Freire, sugerindo que sua filosofia moral está construída sobre uma abordagem dialética do mundo, uma percepção praxiológica do saber e do ideal humano, e um profundo compromisso com a libertação dos oprimidos. Consideramos, assim como Roberts, que o projeto educativo de Paulo Freire é um projeto libertador. Desde seu início, os círculos de cultura incluíram não somente uma denúncia - a das situações de dominação que impedem ao homem ser homem - como também uma afirmação da capacidade criadora de todo ser humano, mesmo do mais oprimido. Daí a necessidade de atuar sobre a realidade social para transformá-la, ação que é interação, comunicação, diálogo.

No texto "Repensando à conscientização" 27 (ROBERTS, 1996b), por exemplo, Roberts se posiciona por uma nova forma de pensar o modelo de níveis de consciência no processo de conscientização proposto por Freire.
24 Freire actively encouraged his readers to adopt a critical posture when encountering his work. For me, as for Freire, such a stance must also be respectful. We need to give an author a fair hearing, seeking out what is potentially valuable in his or her work, while also being willing to ask some searching questions. We should, as Freire would have said, be ready to both challenge and be challenged by what we are reading (ROBERTS, 2019).

25 Structure, Direction and Rigour in Liberating education.

26 Knowledge, Dialogue and Humanization: The Moral Philosophy of Paulo Freire.

27 Rethinking Conscientisation. 
Rejeitando uma visão individualista da consciência crítica, concentra-se na articulação entre conscientização e práxis, reavaliando o projeto de Freire à luz da noção pós-moderna de múltiplas subjetividades. Não haveria, portanto, estágios fixos de consciência com características distintivas bem definidas em cada nível. As pessoas experimentam, envolvem-se e constroem a realidade social de diferentes maneiras, dentro de diferentes discursos, circunstâncias materiais e momentos históricos distintos. Conforme destaca Roberts ao longo da entrevista:

Vivemos em uma época chamada de "pós-verdade". Freire diria que a busca da verdade ainda deve importar, tanto agora como em qualquer outra época da história humana. Ele alertaria, no entanto, contra se tornar muito certo de nossas certezas; devemos sempre permanecer abertos à possibilidade de ver o mundo de outra forma. Em partes do nosso mundo hoje também vemos crescente divisão e ódio; Freire enfatizou a necessidade de unidade na diversidade. Ele queria que valorizássemos nossas diferenças e as considerássemos essenciais para uma vida democrática saudável. (ROBERTS, 2019)..$^{28}$

No ensaio "Pedagogia, neoliberalismo e pós-modernidade: reflexões sobre os trabalhos posteriores de Freire"29 (ROBERTS, 2003b), discute sobre os vários livros lançados em língua inglesa em 1998 e $1999^{30}$, posicionando-os no corpus mais amplo dos escritos publicados de Freire. Com base no material dos livros em análise e em outros trabalhos posteriores, Roberts analisa a posição de Freire sobre opressão, libertação e política da diferença. Conclui que, embora Freire tenha adotado uma série de insights de pensadores pós-modernos, as raízes modernistas de sua ontologia, epistemologia e ética ainda podiam ser percebidas em seus últimos escritos.

Seguindo uma perspectiva de pesquisa comparativa, Roberts elabora estudos sobre a obra de Freire frente a outros grandes escritores, como no caso de Hermann Hesse (ROBERTS, 2007). O texto ${ }^{31}$ analisa o romance "O jogo das contas de vidro", o qual é ambientado em Castália, uma "província pedagógica" do século XXIII. O personagem central do livro, Joseph Knecht, passa por um complexo processo de conscientização. O diálogo passa a desempenhar um papel fundamental no desenvolvimento da consciência crítica do personagem. Desse modo, a teoria freiriana é vista como uma ferramenta robusta para a análise dos temas centrais do texto de Hesse.

Em outro momento, Roberts (2005b) traça análises comparativas de Freire com Fiódor Dostoievski, como no caso de "Freire e Dostoievski: incerteza, diálogo e transformação" ${ }^{32}$, em que coteja temas-chave na obra desses
28 We live in a so-called 'post-truth'age. Freire would say that the pursuit of truth should still matter, as much now as at any other time in human history. He would, however, caution against becoming too certain of our certainties; we must always remain open to the possibility of seeing the world otherwise. In parts of our world today we also see growing divisiveness and hatred; Freire stressed the need for unity in diversity. He wanted us to value our differences and to see them as essential to healthy democratic life.

29 Pedagogy, Neoliberalism and Postmodernity: Reflections on Freire's later work.

$30 \mathrm{O}$ autor refere-se às seguintes obras: FREIRE, Paulo. Politics and Education. Los Angeles, CA: UCLA Latin American Center Publications, 1988; FREIRE, Paulo. Pedagogy of Freedom: Ethics, democracy, and civic courage Lanham: Rowman \& Littlefield, 1998; FREIRE Ana Maria Araújo; MACEDO, Donald (Ed.). The Paulo Freire Reader. New York: Continuum, 1988; FLECHA, Ramon; FREIRE, Paulo; GIROUX, Henry; MACEDO, Donald; WILLIS, Paul. Critical Education in the New Information Age. Lanham, MD: Rowman \& Littlefield, 1999.

31 Conscientisation in Castalia: a Freirean Reading of Hermann Hesse's The Glass Bead Game (ROBERTS, 2007).

32 Freire and Dostoevsky: Uncertainty, dialogue and Transformation (ROBERTS, 2005b). 
autores. Ele indica que, apesar de suas aparentes diferenças, ambos teriam muito em comum. Argumenta que, a partir de uma leitura cuidadosa dos romances de Dostoievski e dos textos pedagógicos de Freire, é possível aprofundar a compreensão do significado de incerteza, diálogo, amor e da luta por uma educação transformadora.

Como exemplo de sua postura crítica e respeitosa, citamos o caso do texto "Defendendo a intervenção freireana"33 (ROBERTS, 1996a), em que Roberts analisa o trabalho de Bowers, intitulado "Raízes linguísticas da invasão cultural na Pedagogia de Paulo Freire ${ }^{34}$ ". Conforme menciona o autor, Bowers argumenta que os programas de alfabetização para adultos elaborados por Freire, ao confrontarem sistemas tradicionais de autoridade e crença, eram potencialmente invasivos e hegemônicos. Para Roberts, essa posição, apesar de apresentar críticas interessantes sobre as formas que educadores interveem na vida de seus educandos, denota conservadorismo cultural e romantiza as culturas "tradicionais". O argumento central de Roberts, ao criticar a posição de Bowers, é que em Freire todo ato educativo gera uma intervenção, mas não necessariamente uma imposição. A intervenção freireana, por exemplo, seria baseada no respeito, na reflexão crítica e na aprendizagem através da experiência.

Outro exemplo que localizamos essa estratégia de crítica apresentada no parágrafo anterior é no texto "Paulo Freire e a política da educação: resposta a Neumann" (2016). Neste artigo, Roberts esclarece que, embora a leitura de Jacob Neumann sobre o seu livro "Paulo Freire no século XXI: educação, diálogo e transformação" forneça subsídios perspicazes e úteis sobre a importância de contextualizar o trabalho e as ideias de Freire, o uso do termo "apolítico" por Neumann é, no entanto, bastante problemático. Roberts argumenta que a educação de uma perspectiva freireana é sempre política; logo, o questionamento deve ser sobre qual o tipo de política estamos personificando em sala de aula.

\section{Considerações finais}

Neste trabalho, tivemos a oportunidade de dar visibilidade no Brasil à discussão da obra de Freire em Aotearoa - Nova Zelândia, a partir da produção acadêmica de Peter Roberts, professor na University of Canterbury.

É impressionante observar a dedicação de um pesquisador não brasileiro, por três décadas, sobre o pensamento de Freire, buscando acompanhar as novas publicações bem como autores que discutem sua obra.

Em diversos momentos, Peter Roberts evidencia o papel e a importância do legado de Freire em sua trajetória, sem, contudo, cair em uma idolatria inconsequente. Conforme esclarece na apresentação de um de seus livros, o contato com a obra de Freire vem desde o final dos anos 1980:
33 Defending Freirean intervention. (ROBERTS, 1996a).

34 Ver: BOWERS, Chet A. Linguistic Roots of Cultural Invasion in Paulo Freire's Pedagogy. Teachers College Record, v. 84, n. 4, p. 365-390, 1983. 
Naquela época, encontrei sua filosofia educacional envolvente e instigante. Eu continuo a encontrar surpresas em seus escritos ainda hoje. O trabalho de Freire tem suas fraquezas, e elas devem ser reconhecidas, mas nenhuma teoria pode fornecer todas as respostas às questões pedagógicas. Freire é, então, apenas uma parte de uma jornada educacional maior. (ROBERTS, 2010, p. VII).

Ao final deste trabalho, entendemos que foi um grande aprendizado conhecer o modo que Peter Roberts percebe e vive o legado de Freire, como pesquisador ou como docente. A seriedade, o compromisso, o reconhecimento e o respeito pelo autor, mundialmente valorizado, reforça a certeza de que Freire tem ainda ressonância e relevância em questões políticas, educacionais, sociais, éticas, filosóficas e humanas.

Em síntese, dentre as diferentes estratégias de sua produção destacamos: i) estudos comparativos entre Freire e autores de obras literárias e/ou filosóficas; ii) acompanhamento a produção de Freire ao longo do tempo sem perder a dimensão histórica; iii) análise de autores que criticam Freire e a partir de seus postulados, tecendo argumentos justificativos que demonstram certa fragilidade nas críticas elaboradas.

Além disso, Roberts nos dá uma pista para compreendermos por que o pensamento de Freire é atual, transcende fronteiras e reflete a realidade de tantos países:

A Nova Zelândia, como o Brasil e muitos outros países, tem estado sujeita a um amplo processo de reforma da política neoliberal. Isso está em curso na Nova Zelândia desde 1984. Em seus últimos trabalhos, Freire foi altamente crítico em relação ao neoliberalismo e à ética do mercado. As ideias de Freire possibilitam refletir fortemente sobre alternativas sociais e econômicas ao neoliberalismo. ${ }^{35}$ (ROBERTS, entrevista, 2019).

Por fim, com este trabalho, esperamos que a produção do pesquisador neozelandês seja reconhecida como uma forte contribuição do legado de Freire.

\section{Referências}

CACEDOVAlO. Paulo Freire - o Patrono da Educação Brasileira (Olavo de Carvalho). 6 maio 2012. 1 vídeo (6 min $31 \mathrm{~s}$ ). Disponível em: https://www.youtube.com/ watch?v=-Mlc68kAuA8. Acesso em: 10 abr. 2019.

CANAL DO STOPPA. Por que Paulo Freire incomoda tanto Bolsonaro?. 15 abr. 2019. 1 post (5 min $44 \mathrm{~s}$ ). Disponível
35 New Zealand, like Brazil and many other countries, has been subject to a wide-ranging process of neoliberal policy reform. This has been underway in New Zealand since 1984. In his later work, Freire was highly critical of neoliberalism and the ethics of the market. Taking Freire's ideas seriously provides one way of actively exploring social and economic alternatives to neoliberalism. 
em: https://www.youtube.com/watch?v=a2sbL6vSf_o. Acesso em: 10 abr. 2019.

CENTRAL DE OPOSIÇÃO. Eduardo Bolsonaro escracha Paulo Freire e desmascara Jandira Feghali. 5 maio 2017. 1 vídeo (13 min 4 s). Disponível em: https:// www.youtube.com/watch?v=a7oOzAL8Vyc. Acesso em: ?

FREIRE, Paulo. Pedagogia do oprimido. Rio de Janeiro: Paz e Terra, 1974.

FREIRE, Paulo. Pedagogia da esperança: um reencontro com a Pedagogia do Oprimido. Rio de Janeiro: Paz e Terra, 1992.

FREIRE, Paulo. Pedagogia da Autonomia: saberes necessários à prática educativa. Rio de Janeiro: Paz e Terra, 1994.

GREEN, Elliot. What are the most-cited publications in the social sciences (according to Google Scholar)?. 2016. The Impact Blog, The London School of Economics and Political Science. Disponível em: http://blogs. lse.ac.uk/impactofsocialsciences/2016/05/12/what-arethe-most-cited-publications-in-the-social-sciences-according-to-google-schola. Acesso em: 19 abr. 2019.

HADDAD, Sérgio. Por que o Brasil de Olavo e Bolsonaro vê em Paulo Freire um inimigo. 14 abr. 2019. Disponível em: https://www1.folha.uol.com.br/ilustrissi$\mathrm{ma} / 2019 / 04 /$ por-que-o-brasil-de-olavo-e-bolsonaro-ve-em-paulo-freire-um-inimigo.shtml. Acesso em: $19 \mathrm{abr}$. 2019.

ROBERTS, Peter. Defending Freirean intervention. Educational Theory, v. 46, n. 3, p. 335-352, 1996 a.

ROBERTS, Peter. Rethinking conscientisation. Journal of Philosophy of Education, v. 30, n. 2, p. 179-196, 1996b.

ROBERTS, Peter. Structure, direction and rigour in liberating education. Oxford Review of Time Educational Review, v. 50, n. 2, p. 105-114, 1996 c.

ROBERTS, Peter. Paulo Freire and political correctness. Great Books and the University Curriculum. In: PETERS, Michael (Ed.). Cultural Politics and the University. Palmerston North: Dunmore Press, 1997. p. 103-134.

ROBERTS, Peter. Knowledge, dialogue, and humanization: the moral philosophy of Paulo Freire, Journal of Educational Thought, v. 32, n. 2, p. 95-117, 1998.

ROBERTS, Peter. A dilemma for critical educators?. Journal of Moral Education, v. 28, n. 1, p. 19-30, 1999a. 
ROBERTS, Peter (Org.). Paulo Freire, politics and pedagogy: reflections from Aotearoa-New Zealand. Palmerston North: Dunmore Press, 1999b.

ROBERTS, Peter. Education, literacy, and humanization: Exploring the work of Paulo Freire. Westport, CT: Bergin and Garvey, 2000.

ROBERTS, Peter. Epistemology, ethics and education: Addressing dilemmas of difference in the work of Paulo Freire. Studies in Philosophy and Education, v. 22, n. 2, p. 157-173, $2003 \mathrm{a}$.

ROBERTS, Peter. Pedagogy, neoliberalism and postmodernity: Reflections on Freire's later work. Educational Philosophy and Theory, v. 35, n. 4, p. 451-465, 2003b.

ROBERTS, Peter. A framework for analysing definitions of literacy. Educational Studies, v. 31, n. 1, p. 29-38, 2005a.

ROBERTS, Peter. Freire and Dostoevsky: Uncertainty, dialogue and transformation. Journal of Transformative Education, v. 3, n. 1, p. 126-139, 2005ab.

ROBERTS, Peter. Conscientisation in Castalia: A Freirean reading of Hermann Hesse's The Glass Bead Game. Studies in Philosophy and Education, v. 26, n. 6, p. 509-523, 2007.

ROBERTS, Peter. Reason, emotion, and politics in the work of Paulo Freire. In: TORRES, Carlos Alberto; NOGUEIRA, Pedro (Ed.) Social Justice Education for Teachers: Paulo Freire and the Possible Dream, Rotterdam: Sense Publishers, 2008. p. 101-118.

ROBERTS, Peter. Paulo Freire in the $\mathbf{2 1}^{\text {st }}$ century: Education, dialogue and transformation. Boulder, CO: Paradigm Publishers, 2010.

ROBERTS, Peter. Bridging East and West - or, a bridge too far? Paulo Freire and the Tao Te Ching. Educational Philosophy and Theory, v. 44, n. 9, p. 942-958, 2012.

ROBERTS, Peter. Paulo Freire and Utopian Education. Review of education, pedagogy, and cultural studies, v. 37, n. 5, p. 376-392, 2015.

ROBERTS, Peter. Happiness, hope, and despair: Rethinking the role of education. New York: Peter Lang, 2016.

ROBERTS, Peter. Impure neoliberalism: A Freirean critique of dominant trends in higher education. Rizoma Freireano, n. 22, p. 1-18, 2017a. 
ROBERTS, Peter. Learning to live with doubt: Kierkegaard, Freire, and critical pedagogy. Policy Futures in Education, v. 15, n. 7/8, p. 834-848, 2017 b.

ROBERTS, Peter. Entrevista. 18 abr. 2019.

ROBERTS, Peter; FREEMAN-MOIR, John. Better worlds: Education, art, and utopia. Lanham, MD: Lexington Books, 2013.

Recebido em: 06/05/2019 Aprovado em: 21/11/2019

Publicado em: 20/12/2019 